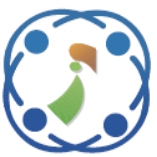

\title{
Modified Artificial Bee Colony Optimization Technique with Different Objective Function of Constraints Optimal Power Flow
}

\author{
Murtadha Al-Kaabi ${ }^{1 *}$ \\ Layth Al-Bahrani \\ ${ }^{1}$ School building department, Rusafa/3, Ministry of Education, Iraq \\ ${ }^{2}$ Faculty Engineering, Mustansiriyah University, Iraq \\ * Corresponding author's Email: mmsk.1986s@gmail.com
}

\begin{abstract}
Artificial Bee Colony (ABC) simulates the behaviour of intelligent foraging for a honeybee swarm. This article deals with one of the best swarm-based algorithms that has been used to solve the Optimal Power Flow (OPF) problem. Minimization of the objecting function can be satisfied by choosing a suitable optimal control variable while maintaining an acceptable system performance of the state variables in terms of their limits. The control variables that used in this article are the magnitude voltage of the generator, the tap changer of the transformer, the injection reactive power of compensative devise and the active power of the generator except the slack generator. The state variables are the reactive power of the generator, the load bus voltage and slack generator active power. The proposed algorithm modifies the classical Artificial bee colony by replacing the worst solutions obtained from the employee bees' phase and the onlooker bees' phase by the best solutions in the swarm size. The percentage of swarm sources that have been selected for the worst solutions is $33 \%, 50 \%$, and randomly selection from the total source of the swarm size. This update contributes to improve the quality of solutions and determine the optimal settings of OPF control variables. The propose algorithm deals with minimization four different objective functions, the total fuel cost of the thermal units, the total active power losses in the transmission lines, the total emission caused by fossil-fueled thermal units and the total voltage deviation at the load buses. The modified ABC reduced the fuel cost by $11.34 \%$, active power losses by $49.26 \%$, voltage deviation by $91.34 \%$ and the emission by $16.70 \%$ satisfying all the constraint of the state variables in their limits. The proposed algorithm has been applied on the IEEE 30 bus system and gives good result when compare with other optimization techniques.
\end{abstract}

Keywords: Artificial bee colony, Optimal power flow, Fuel cost minimization, Active power losses minimization, Emission minimization, Voltage deviation minimization.

\section{Introduction}

One of the most common problems in operating and planning of power system is the Optimal Power Flow (OPF). It was presented by Dommel and Tinney [1]. In the recent years, the optimal power flow problem as usual abundant attention because of its ability to find the optimal solutions to consider the system security [2]. Finding the optimal power system control variables is the main goal of OPF problem to minimize a certain objective function that's sufficient from several equality and inequality constraints. Real power generation levels, voltage magnitude of the generator, tap changer of the transformer and shunt capacitor outputs are the most important control variables of the power system that has been composed. There are two type of optimization techniques that used to solve the OPF problem, the first one is the classical algorithm and second is the modern or artificial intelligence algorithm. To solve the OPF problem and to overcome the limitations of classical optimization techniques, created an evolutionary optimization technique. Many of heuristic optimization techniques was applied such as Simulated Annealing (SA) [3], Genetic Algorithm (GA) [4, 5], Particle Swarm Optimization (PSO) [6], Tabu Search [7], MothFlame Optimizer (MFO) [8], Ant Lion [9], and Differential Evolution algorithm(DE) [10]. The results reported in the literature were promising and encouraging for further research in this direction. 
Artificial Bee Colony (ABC) algorithm is one of the recently heuristic optimization algorithms based on the intelligent behavior of honeybees. It was presented by Karaboga in 2005 [11]. Three phases are involve for each cycle: employed bees phase, onlooker bees phase, and scout bees phase [12-15]. In benchmark problems, $\mathrm{ABC}$ is faster and more efficient than heuristic algorithms as have shown Comparative studies. As a result of its features, ABC algorithm have been effectively used in many power system problems such as optimal reactive power dispatch [16], Enhancing system loadability with multiple FACTS devices [17], Optimal location of UPFC to improve power system voltage stability [18], Optimal power flow in UPFC [19], Economic Dispatch in n power generation [20] and so on.

The formulation and objectives are varied in the OPF problem. So, no optimal algorithm produces for the best solutions for all OPF problems, and therefore there is a continuous need to create a new algorithm to solve the OPF problem with more efficiency.

The goal of using the $\mathrm{ABC}$ algorithm is simplicity, robustness, fewer parameters such as crossover rate and mutation rate in case GA and DE, the convergency is faster, the combination is easier and both exploration and exploitation.

Various methods that used to improve the ABC algorithm have been approached. In [21, 22], the $\mathrm{ABC}$ algorithm was improved by replacing two types of search operations, mutation and crossover of the DE algorithm. M. Chen proposed an improved artificial bee colony algorithm based on escaped foraging strategy [23].

In this article, the improvement of Artificial Bee Colony $\mathrm{ABC}$ is based on replacing the worst swarms by the best swarms in honeybee at each phase (employed bees and onlooker bees). This technique is used to solve the Optimal Power Flow OPF problem with various objective functions such as the total generation fuel costs, the total active power losses, the total amount of emission caused by the fossilfueled thermal units and the voltage profile improvement. Several runs are carried out on the standard IEEE 30-bus test system.

The rest of the article is organized as follows: Section 2 present the notation list of the variables that used in this article. Section 3 describes the mathematical problem formulation with different objective functions. Section 4 present the Artificial Bee Colony (ABC) algorithm in details. Section 5 explain the modified artificial bee colony. Simulation result and comparison with other optimization techniques are given in section 6 . In the last section, the conclusions are drawn from this article.

\section{Nomenclature and abbreviations}

The following notations will used in this paper.

$x^{T} \quad$ vector of state variables.

$u^{T} \quad$ vector of control variables.

$N_{L} \quad$ number of load buses.

$N_{G} \quad$ number of generating units.

$N_{t} \quad$ number of regulating transformers.

$N_{c} \quad$ number of shunt compensators.

$\left|V_{L}\right| \quad$ magnitude voltage of the load bus.

$Q_{G} \quad$ reactive power of the generators.

$P_{G S} \quad$ active power of the slack generator.

$P_{G} \quad$ active power of the generator.

$T \quad$ tap changer of the transformer.

$Q_{C} \quad$ reactive power of shunt injection compensator.

$C_{G i} \quad$ total fuel cost of thermal generator $i$.

$a_{i}, b_{i}, c_{i}$ fuel cost coefficients of the $i^{\text {th }}$ generator.

$P_{G i} \quad$ active power of $i^{t h}$ generator.

$N_{G} \quad$ number of generators with the slack bus.

$P_{\text {loss }} \quad$ active power losses.

$g_{(i, j)} \quad$ line mutual conductance between buses $i, j$.

$V_{i}, V_{j} \quad$ magnitude voltages of the buses $i, j$.

$\delta_{i}, \delta_{j} \quad$ phase angles of the voltages $V_{i}$ and $V_{j}$.

$V_{d} \quad$ total voltage deviation at the load buses.

$V_{i} \quad$ per unit voltage at load bus $i$.

$N_{L} \quad$ number of load buses.

$E_{G i} \quad$ total emission cost (ton/h) of unit $i$.

$\alpha_{i}, \beta_{i}, \gamma_{i}$ emission coefficients of the $i$ th unit.

$N_{B} \quad$ total number of buses except slack bus.

$N_{L} \quad$ total number of load buses.

$P_{i} \quad$ active power injection into $i^{\text {th }}$ bus.

$Q_{i} \quad$ reactive power injection into $i^{\text {th }}$ bus.

$P_{G i} \quad$ active generated at bus $i$.

$Q_{G i} \quad$ reactive power generated at bus $i$.

$P_{d i} \quad$ load active power at bus $i$.

$Q_{d i} \quad$ load reactive power at bus $i$.

$G_{i j}, B_{i j}$ line transfer conductance and susceptance of buses $i, j$ respectively.

$V_{G i}^{\min } \quad$ min. voltage limit of generator $i$.

$V_{G i}^{\max } \max$. voltage limit of generator $i$.

$T_{T i}^{\min }$ min. tap changer limit of transformer $i$.

$T_{T i}^{\max } \max$. tap changer limit of transformer $i$.

$Q_{C i}^{\min }$ min. reactive power compensative devise at load bus $i$.

$Q_{C i}^{\max } \max$. reactive power compensative devise at load bus $i$.

$P_{G i}^{\min } \quad$ min. active power limit of generator $i$ except the slack generator.

$P_{G i}^{\max } \max$ active power limit of generator $i$ except the slack generator.

$V_{L i}^{\min } \min$. voltage of the load bus $i$.

$V_{L i}^{\max }$ max. voltage of the load bus $i$. 


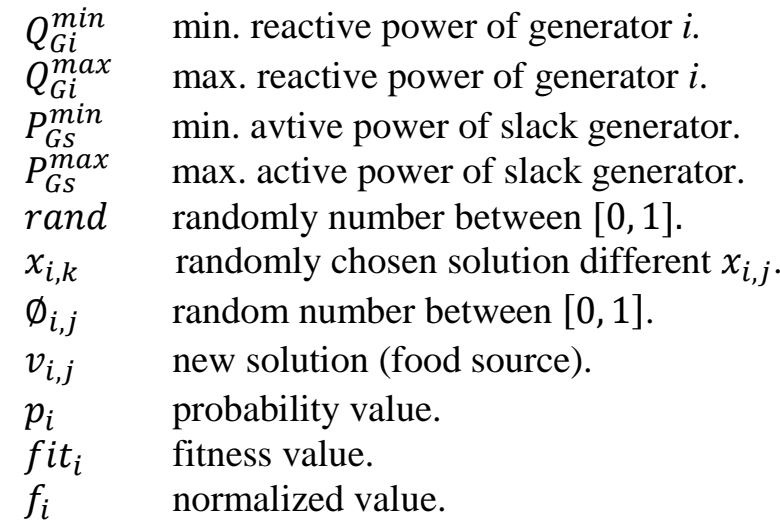

\section{Problem formulation}

The Optimal Power Flow (OPF) can be mathematically formulated as a nonlinear optimization problem. Generally, the OPF problem can be mathematically expressed as follows:

$$
\begin{gathered}
\text { Minimize } f(x, u) \\
\text { subjected to } g(x, u)=0 \\
h(x, u) \leq 0
\end{gathered}
$$

where $f$ is the objective function;

$g$ is the equality constraints of the load flow analysis; $h$ is the constraints of system operating.

The two vectors $x$ and $u$ are expressed in Eqs. (4) and (5) respectively.

$$
\begin{gathered}
x^{T}=\left[\left|V_{L 1}\right|, \ldots,\left|V_{L N_{L}}\right|, Q_{G 1} \ldots Q_{G N_{G}}, P_{G s}\right] \\
u^{T}=\left[P_{G 2}, \ldots, P_{G N_{g}},\left|V_{G_{1}}\right|, \ldots,\left|V_{G N_{G}}\right|, T_{1}, \ldots, T_{N_{t}},\right. \\
\left.Q_{C 1}, \ldots, Q_{C N_{C}}\right]
\end{gathered}
$$

The generators active powers (except slack bus) and generators bus voltages are continuous variables, whereas the tap changing transformers settings and the reactive power injection MVAr of the shunt capacitors are discrete variables.

\subsection{Objective functions}

Four objective functions in this article are considered separately for each one to demonstrate the efficiency of the proposed algorithm.

\subsubsection{Fuel cost minimization}

The total fuel cost objective function of the thermal units can be expressed by:

$$
C_{G i}=\sum_{i=1}^{N_{G}} a_{i} P_{G i}^{2}+b_{i} P_{G i}+c_{i}
$$

where $a_{i}, b_{i}, c_{i}$ are the fuel cost coefficients of the $i^{\text {th }}$ generator;

\subsubsection{The active power losses}

The active power losses of the transmission line can be expressed as:

$$
P_{l o s s}=\sum_{k=1}^{N} g_{(i, j)}\left(V_{i}^{2}+V_{j}^{2}-2 V_{i} V_{j} \cos \delta_{i j}\right)
$$

where $\delta_{i j}=\delta_{i}-\delta_{j}$;

\subsubsection{Minimization of emission}

Due to fossil-fueled thermal units, the atmospheric pollutants product two types of emission gasses, Sulphur oxides $S O_{x}$ and Nitrogen oxides $N O_{x}$. However, the total emission cost is defined as bellow [24]:

$$
\begin{gathered}
E_{G i}=\sum_{i=1}^{N_{G}} 10^{-2}\left(\alpha_{i}+\beta_{i} P_{G_{i}}+\gamma_{i} P_{G_{i}}^{2}\right) \\
+\zeta_{i} \exp \left(\lambda_{i} P_{G i}\right)
\end{gathered}
$$

where $E_{G i}$ is the total emission cost (ton/h) and $\alpha_{i}, \beta_{i}$, $\gamma_{i}$, are the emission coefficients of the $i$ th unit.

\subsubsection{The voltage profile improvement}

The voltage profile improvement at load buses can be realized by minimizing the load bus voltage deviation from 1.0 per unit. The load bus voltage deviation can be expressed as:

$$
V_{d}=\sum_{i=1}^{N_{L}}\left|V_{i}\right|-1
$$

where $V_{d}$ is the total voltage deviation at the load buses; $V_{i}$ the per unit voltage at load bus $i$ and $N_{L}$ is the number of load buses [25].

\subsection{Objective constraints}

The objective functions optimization is determined to a number of equality and inequality constraints 


\subsubsection{Equality constraints}

The equality constraints represent the equations:

Active power balance constraints

$$
\begin{gathered}
\sum_{i=1}^{N_{B}} P_{i}=P_{G i}-P_{d i}= \\
V_{i} \sum_{j=1}^{N_{B}} V_{j}\left[G_{i j} \cos \theta_{i j}+G_{i j} \cos \theta_{i j}\right]
\end{gathered}
$$

- Reactive power balance constraints

$$
\begin{gathered}
\sum_{i=1}^{N_{L}} P_{i}=P_{G i}-P_{d i}= \\
V_{i} \sum_{j=1}^{N_{L}} V_{j}\left[G_{i j} \sin \theta_{i j}+G_{i j} \sin \theta_{i j}\right]
\end{gathered}
$$

where $\theta_{i j}=\theta_{i}-\theta_{j}$;

\subsubsection{Inequality constraints}

These constraints have two type

$$
\begin{gathered}
V_{G i}^{\min } \leq V_{G i} \leq V_{G i}^{\max } \quad i=1,2, \ldots \ldots, N_{L} \\
T_{i}^{\text {min }} \leq T_{i} \leq T_{i}^{\text {max }} \quad i=1,2, \ldots \ldots, N_{T} \\
Q_{C i}^{\min } \leq Q_{G i} \leq Q_{C i}^{\max } \quad i=1,2, \ldots \ldots, N_{C} \\
P_{G i}^{\min } \leq P_{G i} \leq P_{G i}^{\max } \quad i=1,2, \ldots \ldots, N_{G}-1
\end{gathered}
$$

- The inequality constraints on state variable

$$
\begin{gathered}
V_{L i}^{\min } \leq V_{L i} \leq V_{L i}^{\max } i=1,2, \ldots \ldots, N_{L} \\
Q_{G i}^{\min } \leq Q_{G i} \leq Q_{G i}^{\max } i=1,2, \ldots \ldots, N_{G} \\
P_{G S}^{\min } \leq P_{G S} \leq P_{G S}^{\max }
\end{gathered}
$$

\section{Artificial bee colony (ABC) algorithm}

Artificial bee colony is presented by Karaboga for numerical optimization [11]. It simulates the behavior of intelligent foraging for honeybee swarms. It is a robust, simple and population based stochastic optimization algorithm. The food source refers to a probable solution and the nectar amount of a food source represents the quality (fitness) of the related solution of the problem to be optimized. The number of solutions is equal to the number of employed bees or the onlooker bees.

In the first step, the $\mathrm{ABC}$ algorithm produces initial population with randomly distributed in the range of variables (employed bees or onlooker bees) $x_{i}(i=1,2, \ldots, S N)$ is a D-dimensional vector, where $S N$ denotes the size of employed bees or onlooker bees. Eq. (19) used to find a new source by using the following expression:

$x_{i, j}=x_{j, \min }+\operatorname{rand}[0,1] \times\left(x_{j, \min }-x_{j, \min }\right)$

where $x_{j, \min }$ and $x_{j, \max }$ are the minimum and maximum limits of variables to be optimized, and rand denotes a randomly number between $[0,1]$.

Secondly, the population of the positions (solutions) is subjected to repeated cycles, $\mathrm{Y}=1$, $2, \ldots, \mathrm{MCN}$, of the search processes of the employed, onlooker and the scout bees. Employed bees have many of modification on the position in her memory. It will be produced according to the local information and the nectar amount (fitness value) of the new source. If the new nectar amount has equal or better than that of the previous one, it replaces the previous one in her memory. Otherwise, the old one is retained in her memory. Each employed bee identifies new sources whose amounts are equal to the half of the total sources. In order to produce a new food source from the old one saved in the memory; the following expression is used:

$$
v_{i, j}=x_{i, j}+\emptyset_{i, j} \times\left(x_{i, j}-x_{i, k}\right)
$$

In Eq. (20), $k \in\{1, \ldots, S N\}$ and $j \in\{1, \ldots, D\}$ are randomly chosen indexes, where, $D$ is the number of optimization parameters; $S N$ denotes the size of employed bees or onlooker bees; $x_{i, k}$ is a randomly chosen solution different from $x_{i, j}, \emptyset_{i, j}$ is a random number between $[0,1]$ and $v_{i, j}$ denoted the new solution (food source).

In the third step, all food source information will share between employed bees and onlooker bees and select a food source depending on the probability given in Eq. (21)

$$
p_{i}=\frac{f i t_{i}}{\sum_{n=1}^{S N} f i t_{i}}
$$

where $p_{i}$ and $f i t_{i}$ are the probability and the fitness value associated with of the solution $i$. If the 
nectar amount is equal or better than that of the old one, it keeps the new one and abandoned the old one. For simplifying problem, the following expression are used to calculate $f i t_{i}$ :

$$
\text { fit }_{i}= \begin{cases}\frac{1}{1+f_{i}} & \text { if } f_{i} \geq 0 \\ 1+f_{i} & \text { if } f_{i}<0\end{cases}
$$

where $f_{i}$ represents the normalized value for the objective function. Finally, the scout bees are mainly responsible for a new food source randomly in each colony. They are chosen from the employed bees with taking into consideration the limit parameters. The employed bee will be a scout when the food source is not improved by the predetermined number of trials. The number of incomings and outgoings to a source is an important control parameter and which is called "limit". The expression which identifies a scout bee is given in Eq. (19).

\section{Modified artificial bee colony}

To achieve optimal optimization performance, the ability of exploration and exploitation must be well balanced. In the ABC algorithm, the onlooker carries out the exploitation process and the exploration process are accomplished by employed and scout bees. This algorithm is modified by determining the best solutions (minimum objective function) and the worst solutions (maximum objective function) in descending order, then delete the worst solutions and replaced by the best solutions for each phase (the employed bee and onlooker bee) at each iteration according to three types of swarm source shown below as followed:

1- Type 1: the percentage of the worst solutions of employed bees and onlooker bees is 33\% and $67 \%$ respectively.

2- Type 2: the percentages of the worst solutions of employed bees and the onlooker bee are $50 \%$.

3- Type 3: randomly choosing to determine the worst solutions for both bees.

To demonstrate the effectiveness and strength of this technique, the three types of swarm source are used to minimize different objective function depending on the percentage that have been selected from the worst solutions and replacing them with the best solutions in the employee bees phase and the onlooker bees phase in the swarm size.

Fig. 1 illustrates the flow chart of proposed MABC algorithm.

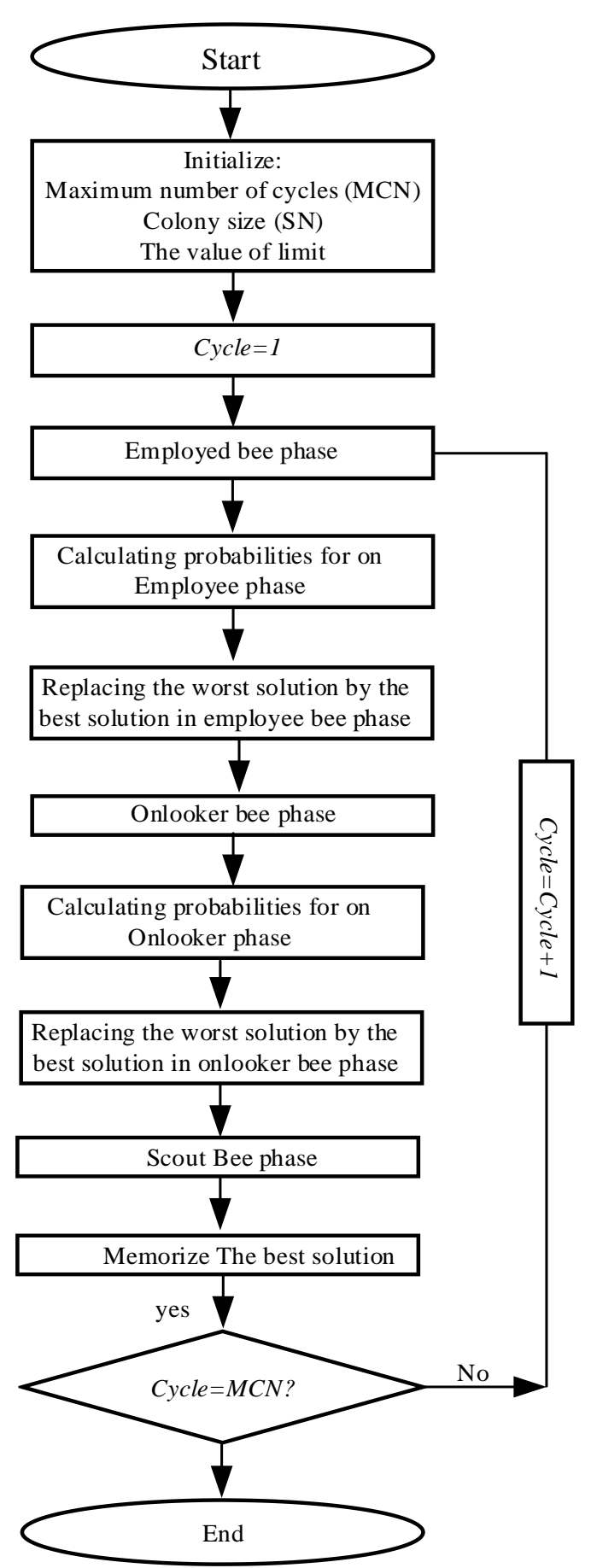

Figure. 1 Flowchart of proposed MABC algorithm

\section{Simulation result}

Applying the artificial bees algorithm to solve the OPF problem was carried out on the IEEE-30 bus systems and compared its simulation results with those of GA, PSO, DE, ABC, TSA, SCA, SFLA and JA $[5,10,16,25-40]$. The generation cost and emission coefficients of IEEE-30 bus system given in Table 1 and Table 2 respectively. The system contains 6 generation stations with 4 transformers and 41 transmission lines as shown in Fig. 2 [28]. 
Table 1. Generation cost coefficients for IEEE30 bus

\begin{tabular}{|c|c|c|c|}
\hline \multirow{2}{*}{$\begin{array}{c}\text { Bus } \\
\text { No. }\end{array}$} & \multicolumn{3}{|c|}{ Cost coefficients } \\
\hline 1 & $\boldsymbol{a}$ & $\boldsymbol{B}$ & $\boldsymbol{C}$ \\
\hline 2 & 0 & 2 & $3.7 \mathrm{ee}-3$ \\
\hline 5 & 0 & 1.75 & $1.75 \mathrm{e}-2$ \\
\hline 8 & 0 & 1 & $6.25 \mathrm{E}-2$ \\
\hline 11 & 0 & 3.25 & $8.3 \mathrm{E}-3$ \\
\hline 13 & 0 & 3 & $2.5 \mathrm{E}-2$ \\
\hline
\end{tabular}

Table 2. Generation emission coefficients for IEEE30 bus

\begin{tabular}{|c|c|c|c|c|c|}
\hline \multirow{2}{*}{$\begin{array}{c}\text { Bus } \\
\text { No. }\end{array}$} & \multicolumn{5}{|c|}{ Emission coefficients } \\
\cline { 2 - 6 } & $\boldsymbol{\alpha}$ & $\boldsymbol{\beta}$ & $\gamma$ & $\boldsymbol{\zeta}$ & $\boldsymbol{\lambda}$ \\
\hline 1 & 4.091 & -5.554 & 6.490 & $2.0 \mathrm{e}-4$ & 2.857 \\
\hline 2 & 2.543 & -6.047 & 5.638 & $5.0 \mathrm{e}-4$ & 3.33 \\
\hline 5 & 4.258 & -5.094 & 4.586 & $1.0 \mathrm{e}-6$ & 8.0 \\
\hline 8 & 5.326 & -3.550 & 3.380 & $2.0 \mathrm{e}-3$ & 2.0 \\
\hline 11 & 4.258 & -5.094 & 4.586 & $1.0 \mathrm{e}-6$ & 8.0 \\
\hline 13 & 6.131 & -5.555 & 5.151 & $1.0 \mathrm{e}-5$ & 6.67 \\
\hline
\end{tabular}

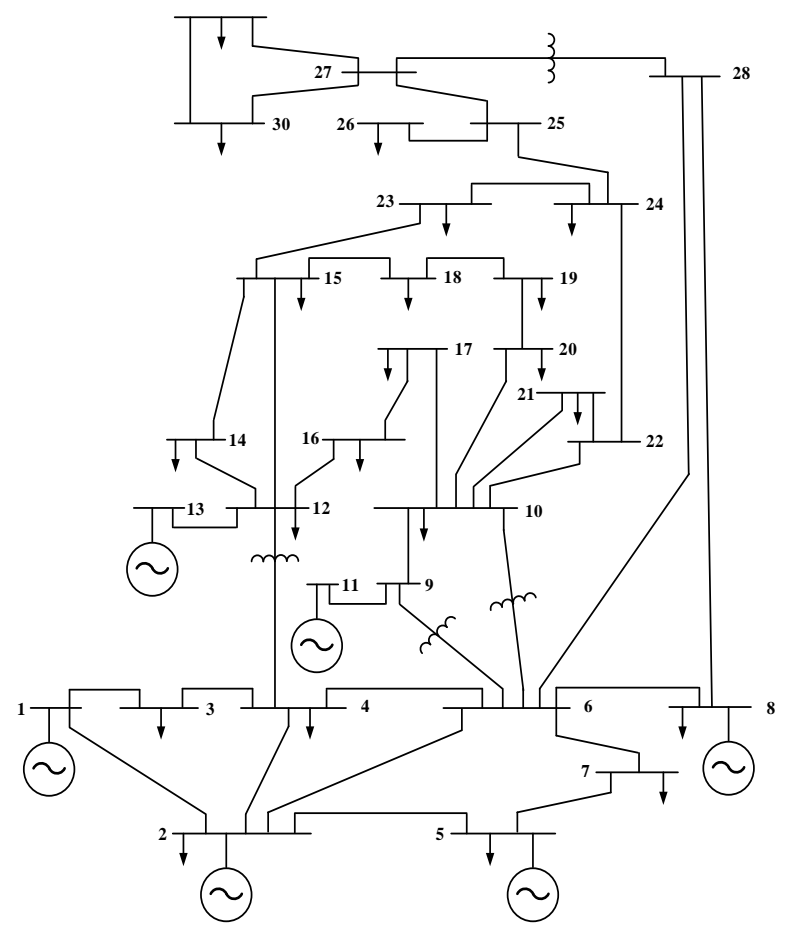

Figure. 2 Single-line diagram of IEEE 30-bus test system

Table 3. Comparison of proportional the swarm source

\begin{tabular}{|c|c|c|c|c|}
\hline \multirow{2}{*}{ Types } & \multicolumn{4}{|c|}{ Objective Function } \\
\cline { 2 - 5 } & $\begin{array}{c}\text { Fuel } \\
\text { cost } \\
(\$ / \mathrm{h})\end{array}$ & $\begin{array}{c}\text { Active } \\
\text { losses } \\
(\mathrm{MW})\end{array}$ & $\begin{array}{c}\text { Emission } \\
(\text { ton} / \mathrm{h})\end{array}$ & $\begin{array}{c}\text { Voltage } \\
\text { deviation } \\
(\mathrm{pu})\end{array}$ \\
\hline Type 1 & 799.58 & 2.8864 & 0.2048 & 0.1069 \\
\hline Type 2 & 799.38 & 2.8969 & 0.2048 & 0.1017 \\
\hline Type 3 & 799.40 & 2.8894 & 0.2048 & 0.1197 \\
\hline
\end{tabular}

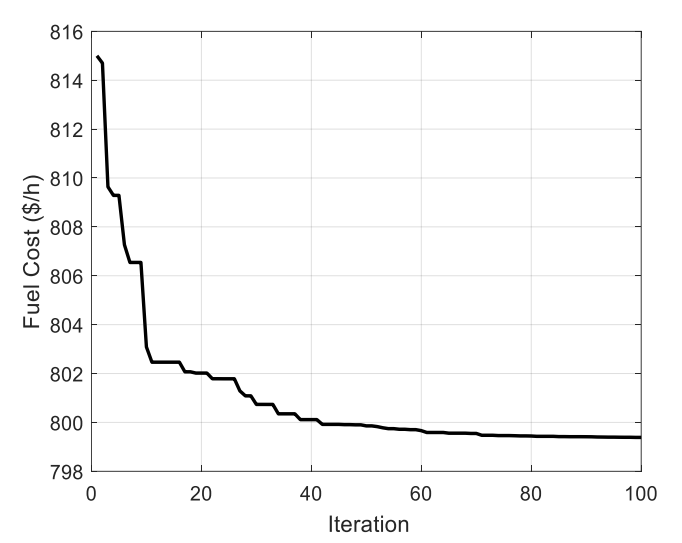

Figure. 3 The convergence plot for fuel cost function

\subsection{Case 1: Fuel cost minimization}

The objective function is to minimize the fuel cost $C_{G}$ that defined in Eq. (6). The minimum fuel cost obtained from the modified ABC approach based on the three types of swarm source type 1 , type 2 and type 3 was $799.5893 \$ / \mathrm{h}, 799.3862 \$ / \mathrm{h}$ and 799.4071 $\$ / \mathrm{h}$ respectively as shown in Table 3 . Fig. 3 shows the fast convergence to the optimal solution based on type 2 (the best one). Table 4 illustrate control variables of OPF for the best solution. The fuel cost is reduced from the initial value $901.6391 \$ / \mathrm{h}$ to optimal value $799.386 \$ / \mathrm{h}$ with reduction equal to $11.34 \%$.

\subsection{Case 2: Active power losses minimization}

In this case, the objective function is to minimize the active power losses $P_{\text {loss }}$ that defined in equation (7). According to the three types of the swarm source of the modified ABC type 1, 2 and 3, the minimum active power losses was $2.8864 \mathrm{MW}, 2.8969 \mathrm{MW}$ and $2.8894 \mathrm{MW}$ respectively as shown in Table 3. The best solution is given in type 1. Fig. 4 shows the convergence of the minimum active power losses based on type 1 (the best one). The total active power losses are reduced by up to $49.26 \%$ compared to the initial active power losses 5.6891 MW as shown in Table 4 where the optimal active power losses for the best type of the swarm source was $2.8864 \mathrm{MW}$.

\subsection{Case 3: Emission cost minimization}

The total emission minimization of the generators $E_{G}$ is defined in Eq. (8). All the three types of swarm source are equally for the best solution as shown in Table 3. The total emission reduced from the initial value $0.239 \mathrm{ton} / \mathrm{h}$ to the optimal value $0.2048 \mathrm{ton} / \mathrm{h}$ with reduction ratio of $16.7 \%$ as given in Table 4 . Fig. 5 illustrates the convergence characteristic of the 
Table 4. Control variables and result simulation for the best objective functions

\begin{tabular}{|c|c|c|c|c|c|c|c|c|}
\hline \multirow{2}{*}{\multicolumn{2}{|c|}{ Control variables }} & \multirow{2}{*}{\multicolumn{2}{|c|}{ Limit }} & \multirow{2}{*}{$\begin{array}{c}\text { Initial } \\
\\
80 \\
\end{array}$} & \multirow{2}{*}{\begin{tabular}{|c|} 
Fuel cost \\
48.7538 \\
\end{tabular}} & \multirow{2}{*}{$\begin{array}{c}\begin{array}{c}\text { Active } \\
\text { power losses }\end{array} \\
79.9959 \\
\end{array}$} & \multirow{2}{*}{\begin{tabular}{|c|}
$\begin{array}{c}\text { Voltage } \\
\text { deviation }\end{array}$ \\
33.7391 \\
\end{tabular}} & \multirow{2}{*}{$\begin{array}{l}\text { Emission } \\
67.1785 \\
\end{array}$} \\
\hline & & & & & & & & \\
\hline \multirow{5}{*}{ 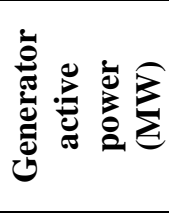 } & $P_{2}$ & $\begin{array}{c}\mathbf{M a} \\
\mathbf{x} \\
20 \\
\end{array}$ & $\begin{array}{c}\text { Min } \\
80 \\
\end{array}$ & & & & & \\
\hline & $P_{5}$ & 15 & 50 & 50 & 21.1924 & 49.994 & 38.424 & 49.9998 \\
\hline & $P_{8}$ & 10 & 35 & 20 & 21.4388 & 34.9975 & 33.6407 & 34.9997 \\
\hline & $P_{11}$ & 10 & 30 & 20 & 11.6952 & 29.9994 & 29.1491 & 29.9991 \\
\hline & $P_{13}$ & 12 & 40 & 20 & 12.0059 & 39.9997 & 13.0961 & 39.9997 \\
\hline \multirow{6}{*}{ 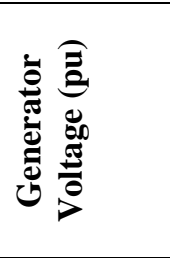 } & $V_{1}$ & 0.95 & 1.1 & 1.05 & 1.1 & 1.0998 & 1.0188 & 1.1 \\
\hline & $V_{2}$ & 0.95 & 1.1 & 1.04 & 1.0871 & 1.0969 & 1.0122 & 1.0973 \\
\hline & $V_{5}$ & 0.95 & 1.1 & 1.01 & 1.0612 & 1.0773 & 1.0178 & 1.0817 \\
\hline & $V_{8}$ & 0.95 & 1.1 & 1.01 & 1.0679 & 1.0855 & 1.0113 & 1.0872 \\
\hline & $V_{11}$ & 0.95 & 1.1 & 1.05 & 1.0996 & 1.0999 & 1.0387 & 1.0989 \\
\hline & $V_{13}$ & 0.95 & 1.1 & 1.05 & 1.0991 & 1.1 & 0.9972 & 1.0999 \\
\hline \multirow{4}{*}{ สิ } & $T_{11}$ & 0.9 & 1.1 & 1.078 & 1.0467 & 0.9994 & 0.9532 & 1.0239 \\
\hline & $T_{12}$ & 0.9 & 1.1 & 1.069 & 0.9507 & 1.0232 & 1.0219 & 1.0687 \\
\hline & $T_{15}$ & 0.9 & 1.1 & 1.032 & 1.0988 & 0.9511 & 0.9509 & 0.952 \\
\hline & $T_{36}$ & 0.9 & 1.1 & 1.068 & 0.9841 & 0.9822 & 0.9694 & 0.9953 \\
\hline \multirow{9}{*}{$\underset{\text { 焉 }}{\stackrel{\vec{E}}{E}}$} & $Q_{c 10}$ & 0 & 5 & 0 & 4.9657 & 4.9375 & 4.7634 & 4.4083 \\
\hline & $Q_{C 12}$ & 0 & 5 & 0 & 4.8689 & 4.9835 & 2.997 & 0.0769 \\
\hline & $Q_{c 15}$ & 0 & 5 & 0 & 4.5424 & 4.6936 & 4.7707 & 4.8999 \\
\hline & $Q_{17}$ & 0 & 5 & 0 & 4.9925 & 4.9693 & 0.3197 & 4.6113 \\
\hline & $Q_{c 20}$ & 0 & 5 & 0 & 4.6231 & 4.8142 & 4.937 & 4.4519 \\
\hline & $Q_{21}$ & 0 & 5 & 0 & 4.5904 & 4.9863 & 4.9909 & 4.8163 \\
\hline & $Q_{c 23}$ & 0 & 5 & 0 & 4.6889 & 4.1282 & 4.9569 & 4.9561 \\
\hline & $Q_{24}$ & 0 & 5 & 0 & 4.9371 & 4.9918 & 4.9175 & 4.9868 \\
\hline & $Q_{29}$ & 0 & 5 & 0 & 2.8721 & 3.1465 & 2.9494 & 2.3209 \\
\hline \multicolumn{2}{|c|}{ Fuel cost $(\$ / \mathbf{h})$} & & & 901.6391 & 799.386 & 967.1569 & 840.989 & 943.3064 \\
\hline \multicolumn{2}{|c|}{ Power losses (MW) } & & & 5.6891 & 8.6928 & 2.8864 & 6.8492 & 3.0385 \\
\hline \multicolumn{2}{|c|}{ Voltage deviation } & & & 1.1747 & 1.4212 & 0.1499 & 0.1017 & 1.6315 \\
\hline \multicolumn{2}{|c|}{ Emission } & & & 0.239 & 0.3661 & 0.2072 & 0.2833 & 0.2048 \\
\hline \multicolumn{2}{|c|}{ Reduction ratio } & & & - & $11.34 \%$ & $49.26 \%$ & $91.34 \%$ & $16.70 \%$ \\
\hline \multicolumn{2}{|c|}{$\begin{array}{l}\text { Slack generator } \\
\text { active power } P_{G s}\end{array}$} & 20 & 200 & 99.23 & 177.0267 & 51.3197 & 142.2207 & 64.2819 \\
\hline
\end{tabular}

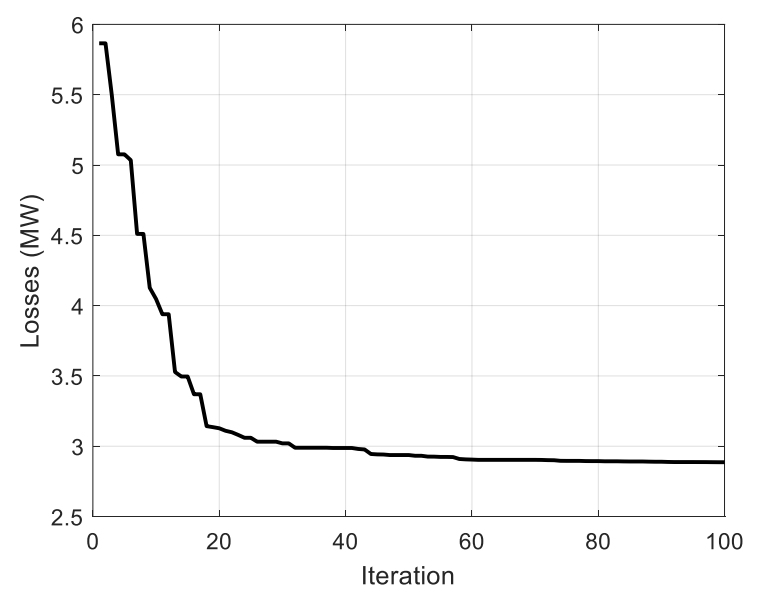

Figure. 4 The convergence plot for power losses function

$\mathrm{ABC}$ algorithm to the global optimal solution for the system after 100 iterations.

\subsection{Case 4: Voltage profile improvement}

In this case, the objective function that taken into consideration is the voltage profile improvement $V_{d}$ which can be achieved by minimization the load bus voltage deviations from 1.0 per unit. This objective function can be expressed as in Eq. (9). The best solution of the system voltage profile was 0.1017 p.u based on type 2 of the swarm source as shown in Table 3. Fig. 6 shows the convergence characteristic curve of the system voltage profile based on type 2 of the proposed $\mathrm{ABC}$ algorithm. The voltage profile is greatly improved compared with the other pervious objective function, where the total voltage deviations is reduced from the initial value $1.1747 \mathrm{pu}$ to the optimal value 0.1017 pu with a reduction of $91.34 \%$ as given in Table 4 . 


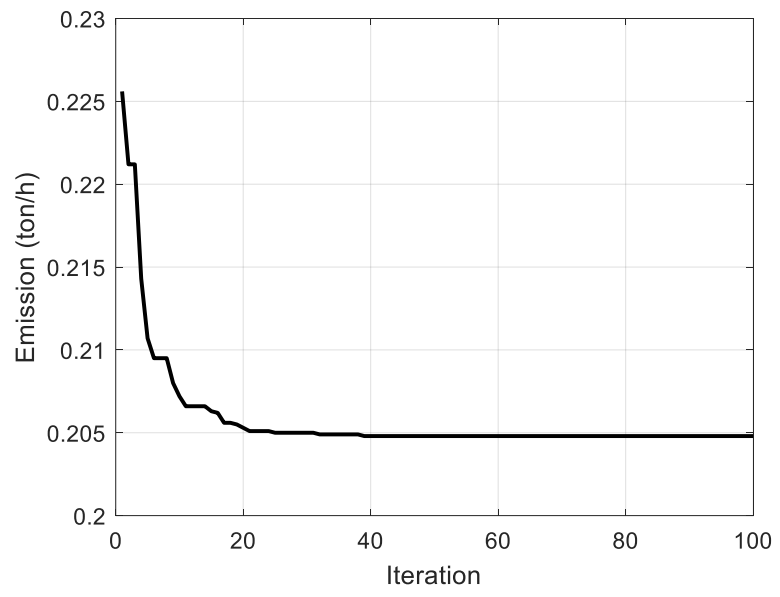

Figure. 5 The Convergence plot for emission function

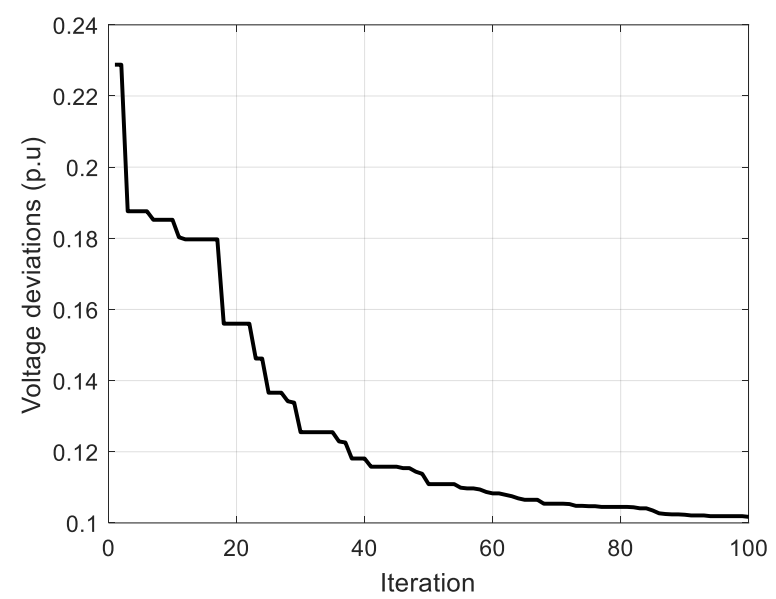

Figure. 6 The Convergence plot for voltage deviation function

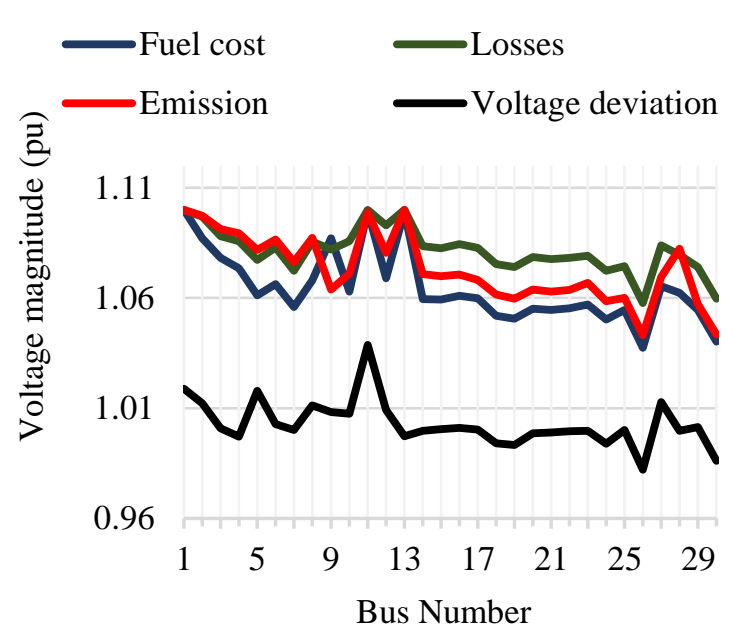

Figure. 7 System voltage profile

The optimal control variables for the best objective function based on the modified $\mathrm{ABC}$ are given in Table 4.

Table 5 illustrate the results of comparison among the proposed modified $\mathrm{ABC}$ algorithm with the other optimization techniques.

The propose algorithm satisfied the constraint OPF by finding the optimal control variables for best objective functions keeping the state variables of the active power of the slack generator, load voltages and the reactive power of the generators in their maximum and minimum limits as shown in Table 4, Table 6 and Fig. 7 respectively.

Table 5. Comparisons of the results obtained using different optimization techniques

\begin{tabular}{|l|c|c|c|c|}
\hline \multicolumn{1}{|c|}{ Methods } & $\begin{array}{c}\text { Fuel cost } \\
\mathbf{( \$ / h )}\end{array}$ & $\begin{array}{c}\text { Active power } \\
\text { losses } \mathbf{( M W )}\end{array}$ & $\begin{array}{c}\text { Emission } \\
\mathbf{( t o n / h )}\end{array}$ & $\begin{array}{c}\text { Voltage } \\
\text { profile (pu) }\end{array}$ \\
\hline Initial & 901.6391 & 5.830 & 0.3661 & 1.1747 \\
\hline IGA [32] & 800.805 & NA & NA & NA \\
\hline Gradient [30] & 804.853 & NA & NA & NA \\
\hline EGA [34] & NA & 3.2008 & NA & NA \\
\hline DE [27] & 800.56 & 3.240 & NA & NA \\
\hline DE [35] & 799.365 & 2.9748 & NA & NA \\
\hline MSLFA [33] & NA & NA & 0.2056 & NA \\
\hline PSO [26] & 801.66 & 3.032 & NA & NA \\
\hline SLFA [33] & NA & NA & 0.2063 & NA \\
\hline ABC [31] & 800.6600 & 3.1078 & 0.204826 & NA \\
\hline MSCA [36] & NA & 2.9334 & NA & 0.1031 \\
\hline IABC [37] & NA & 3.084 & NA & NA \\
\hline GA [33] & NA & NA & 0.21170 & NA \\
\hline Hybrid PSO and GSA [38] & NA & NA & NA & 0.12674 \\
\hline Jaya [39] & NA & NA & NA & 0.1273 \\
\hline (EGA-DQLF) [40] & NA & NA & NA & 0.111 \\
\hline Proposed algorithm ABC & $\mathbf{7 9 9 . 3 8 6 2}$ & $\mathbf{2 . 8 8 6 4}$ & $\mathbf{0 . 2 0 4 8}$ & $\mathbf{0 . 1 0 1 7}$ \\
\hline
\end{tabular}


Table 6. The state variable of reactive power of the generators of OPF based on modified ABC technique

\begin{tabular}{|c|c|c|c|c|c|c|}
\hline $\begin{array}{c}\text { Unit } \\
\text { number }\end{array}$ & $\begin{array}{c}\boldsymbol{Q}_{\boldsymbol{G}_{\boldsymbol{i}}(\mathbf{m i n})} \\
(\mathbf{M V A r})\end{array}$ & $\begin{array}{c}\boldsymbol{Q}_{\boldsymbol{G}_{\boldsymbol{i}}(\mathbf{m a x})} \\
(\mathbf{M V A r})\end{array}$ & $\begin{array}{c}\boldsymbol{Q}_{\boldsymbol{G}_{\boldsymbol{i}}}(\mathbf{M V A r}) \\
\text { for fuel cost }\end{array}$ & $\begin{array}{c}\boldsymbol{Q}_{\boldsymbol{G}_{\boldsymbol{i}}} \text { (MVAr) for } \\
\text { active power losses }\end{array}$ & $\begin{array}{c}\boldsymbol{Q}_{\boldsymbol{G}_{\boldsymbol{i}}}(\mathbf{M V A r}) \text { for } \\
\text { voltage deviation }\end{array}$ & $\begin{array}{c}\boldsymbol{Q}_{\boldsymbol{G}_{\boldsymbol{i}}}(\mathbf{M V A r}) \\
\text { for Emission }\end{array}$ \\
\hline 1 & -20 & 200 & -9.939 & -3.3563 & -17.0454 & -7.83 \\
\hline 2 & -20 & 100 & 30.8858 & 18.5594 & 20.5652 & 19.1057 \\
\hline 5 & -15 & 80 & 32.6568 & 25.5385 & 54.557 & 28.1862 \\
\hline 8 & -15 & 60 & 39.8395 & 35.3486 & 55.2374 & 32.932 \\
\hline 11 & -10 & 50 & 7.0163 & 15.0023 & 16.641 & 19.9798 \\
\hline 13 & -15 & 60 & 23.7225 & 9.6671 & -8.3773 & 16.2358 \\
\hline
\end{tabular}

\section{Conclusions}

This article presented a modifying for the classical Artificial Bee Colony (ABC) to solving Optimal Power Flow problem (OPF). The proposed algorithm demonstrates the robustness, flexibility, effectiveness and successfully applied to solve OPF. To show the effectiveness of this approach, the objective function of fuel cost, active power losses, emission, and voltage deviation have been applied and tested using the IEEE 30-bus system. The modified ABC based on determining the worst solutions for each phase (employed bee phase and onlooker bee phase) then replace its by the best solutions at each iteration to improve the quality of solutions and select the optimal control variables for the best different objective function. The worst solutions that chosen in this algorithm is $33 \%, 50 \%$, and random selection from the total swarm source. The proposed approach has fast convergence and quality solution when compare with other methods in the literature. The performance of $\mathrm{ABC}$ algorithm indicating its effectiveness for solving OPF problems, especially for large systems.

\section{Conflicts of Interest}

The authors identify and declare that there is no any personal circumstances or interest that may be perceived as inappropriately influencing the representation or interpretation of reported research results.

\section{Author Contributions}

Conceptualization, Layeth Al-Bahrani and Murtadha Al-Kaabi; methodology, Layeth AlBahrani and Murtadha Al-Kaabi; software, Layeth Al-Bahrani and Murtadha Al-Kaabi; validation, Murtadha Al-Kaabi; formal analysis, Layeth AlBahrani and Murtadha Al-Kaabi; investigation, Layth Al-Bahrani; resources, Murtadha Al-Kaabi; data curation, Murtadha Al-Kaabi; writing - original draft preparation, Murtadha Al-Kaabi; writingreview and editing, Layth Al-Bahrani; visualization,
Layeth Al-Bahrani, and Murtadha Al-Kaabi; supervision, Layeth Al-Bahrani; project administration, Layeth Al-Bahrani and Murtadha AlKaabi; funding acquisition, Layeth Al-Bahrani, and Murtadha Al-Kaabi.

\section{Acknowledgments}

The authors would like to acknowledge the department of Electrical Engineering, Mustansiriyah University for their encourage and support.

\section{References}

[1] H. Dommel and W. Tinney, "Optimal Power Flow Solutions", IEEE Transactions on Power Apparatus and Systems, Vol. PAS-87, No. 10, pp. 1866-1876, 1968.

[2] M. Kumari and S. Maheswarapu, "Enhanced Genetic Algorithm based computation technique for multi-objective Optimal Power Flow solution", International Journal of Electrical Power and Energy Systems, Vol. 32, No. 6, pp. 736-742, 2010.

[3] V. Miranda, D. Srinivasan, and L. Proença, "Evolutionary computation in power systems", International Journal of Electrical Power and Energy Systems, Vol. 20, No. 2, pp. 89-98, 1998.

[4] L. Lai, J. Ma, R. Yokoyama, and M. Zhao, "Improved genetic algorithms for optimal power flow under both normal and contingent operation States", International Journal of Electrical Power and Energy Systems, Vol. 19, No. 5, pp. 287-292, 1997.

[5] M. Osman, M. Abo-Sinna, and A. Mousa, "A solution to the optimal power flow using genetic algorithm", Applied Mathematics and Computation, Vol. 155, No. 2, pp. 391-405, 2004.

[6] M. Abido, "Optimal power flow using particle swarm optimization", International Journal of Electrical Power and Energy Systems, Vol. 24, No. 7, pp. 563-571, 2002.

[7] M. Abido, "Optimal power flow using tabu search algorithm", Electric power components 
and system, Vol. 30, No. 5, pp. 469-483, 2002.

[8] I. Trivedi, P. Jangir, S. Parmar, and N. Jangir, "Optimal power flow with voltage stability improvement and loss reduction in power system using Moth-Flame Optimizer", Neural Computing and Applications, Vol. 30, No. 6, pp. 1889-1904, 2018.

[9] O. Herbadji, L. Slimani, and T. Bouktir, "Optimal Power Flow With Four Conflicting Objective Functions Using Multiobjective Ant Lion Algorithm: A Case Study of the Algerian Electrical Network", Iranian Journal of Electrical and Electronic Engineering, Vol. 15, No. 1, pp. 94-113, 2019.

[10] A. Abou El Ela, M. Abido, and S. Spea, "Optimal power flow using differential evolution algorithm", Electric Power Systems Research, Vol. 80, No. 7, pp. 878-885, 2010.

[11] D. Karaboga, An idea based on honey bee swarm for numerical optimization, Technical reporttr06, Erciyes University, Engineering Faculty, Computer Engineering Department, 2005.

[12] D. Karaboga and B. Basturk, "A powerful and efficient algorithm for numerical function optimization: Artificial bee colony (ABC) algorithm", Journal of Global Optimization, Vol. 39, No. 3, pp. 459-471, 2007.

[13] D. Karaboga and B. Basturk, "On the performance of artificial bee colony (ABC) algorithm", Applied Soft Computing Journal, Vol. 8, No. 1, pp. 687-697, 2008.

[14] B. Basturk, "An artificial bee colony (ABC) algorithm for numeric function optimization", IEEE Swarm Intelligence Symposium, Indianapolis, IN, USA, 2006.

[15] D. Karaboga and B. Akay, "A comparative study of Artificial Bee Colony algorithm", Applied Mathematics and Computation, Vol. 214, No. 1, pp. 108-132, 2009.

[16] M. Ettappan, V. Vimala, S. Ramesh, and V. Kesavan, "Optimal Reactive Power Dispatch for Real Power Loss Minimization and Voltage Stability Enhancement using Artificial Bee Colony Algorithm", Microprocessors and Microsystems, Vol. 76, 2020.

[17] S. M. Rafee and A. S. Reddy, "Enhancing system loadability with multiple FACTS devices using Artificial Bee Colony Algorithm", EasyChair, Preprint No. 2069, 2019.

[18] B. V. Kumar, "Optimal Location of Upfc to Improve Power System Voltage Stability Using Artificial Bee Colony Algorithm", American Journal of Electrical Power and Energy system, Vol. 8, No. 2, pp. 42-49, 2019.

[19] M. Karthikeyan, "Optimal power flow in UPFC using artificial bee colony and artificial neural network Technique", International Journal in IT \& Engineering, Vol. 5, No .5, pp. 5-21, 2017.

[20] M. Abdullah, A. Manan, J. Jamian, S. Jumaat, and N. Radzi, "Gbest Artificial Bee Colony for Non-Convex Optimal Economic Dispatch in Power Generation", Indonesian Journal of Electrical Engineering and Computer Science, Vol. 11, No. 1, pp. 187-194, 2018.

[21] R. Liang, C. Wu, Y. Chen, and W. Tseng, "Multi-objective dynamic optimal power flow using improved artificial bee colony algorithm based on Pareto optimization", International Transactions on Electrical Energy Systems, Vol. 26, No. 4, pp. 692-712, 2016.

[22] X. He, W. Wang, J. Jiang, and L. Xu, "An Improved Artificial Bee Colony Algorithm and Its Application to Multi-Objective Optimal Power Flow", Energies, Vol. 8, No. 4, pp. 2412 2437, 2015.

[23] M. Chen, "Improved artificial bee colony algorithm based on escaped foraging strategy", Journal of the Chinese Institute of Engineers, Vol. 42, No. 6, pp. 516-524, 2019.

[24] M. Abido, "Environmental/economic power dispatch using multiobjective evolutionary algorithms", IEEE Transactions on Power Apparatus and Systems, Vol. 18, No. 4, pp. 1529-1537, 2003.

[25] L. Al-Bahrani, Optimal Power Flow (OPF) with different Objective Function based on modern heuristic optimization techniques, PhD Thesis, University POLITEHNICA of Bucharest, Romania, 2015.

[26] C. Ravi and C. Rajan, "Emission Constraint Optimal Power Flow using Differential Evolution", International Journal of Computer Applications, Vol. 61, No. 13, 2013.

[27] L. Al-Bahrani and V. Dumbrava, "Optimal Power Flow based on Particle Swarm Optimization", Scientific Bulletin, Series C Electrical Engineering and Computer Science, Vol. 78, No. 3, pp. 253-264, 2016.

[28] M. Abido and N. Al-Ali, "Multi-objective differential evolution for optimal power flow", In: Proc. of International Conference on Power Engineering, Energy and Electrical Drives, Lisbon, Portugal, pp.101-106, 2009.

[29] A. Shrivastava and H. Siddiqui, "A simulation analysis of optimal power flow using differential evolution algorithm for IEEE-30 bus system", International Journal of Recent Development in Engineering and Technology, Vol. 2, No. 3, pp. 50-57, 2014.

[30] K. Lee, Y. Park, and J. L. Ortiz, "A united 
approach to optimal real and reactive power dispatch", IEEE Transactions on Power Apparatus and Systems, Vol. PAS-104, No. 5, pp. 1147-1153, 1985.

[31] M. Adaryani and A. Karami, "Artificial bee colony algorithm for solving multi-objective optimal power flow problem", International Journal of Electrical Power and Energy Systems, Vol. 53, No. 1, pp. 219-230, 2013.

[32] L. Lai, J. Ma, R. Yokoyama, and M. Zhao, "Improved genetic algorithms for optimal power flow under both normal and contingent operation states", International Journal of Electrical Power and Energy Systems, Vol. 19, No. 5, pp. 287-292, 1997.

[33] T. Niknam, M. Narimani, M. Jabbari, and A. Malekpour, "A modified shuffle frog leaping algorithm for multi-objective optimal power flow", Energy, Vol. 36, No. 11, pp. 6420-6432, 2011.

[34] M. Kunari and S. Maheswarapu, "Enhanced genetic algorithm based computation technique for multi-objective optimal power flow", International Journal of Electrical Power and Energy Systems, Vol. 32, No. 6, pp. 736-742, 2010.

[35] L. Al-Bahrani, M. Al-kaabi, M. Al-saadi, and V. Dumbrava, "Optimal Power Flow based on Differential Evolution Optimization Technique", Scientific Bulletin, Series $C$ Electrical Engineering and Computer Science, Vol. 82, No. 1, pp. 247-258, 2020.

[36] A. Attia, R. El Sehiemy, and H. Hasanien, "Optimal power flow solution in power systems using a novel Sine-Cosine algorithm", International Journal of Electrical Power and Energy Systems, Vol. 99, pp. 331-343, 2018.

[37] W. Bai, I. Eke, and K. Lee, "An improved artificial bee colony optimization algorithm based on orthogonal learning for optimal power flow problem", Control Engineering Practice, Vol. 61, pp. 163-172, 2017.

[38] J. Radosavljević, D. Klimenta, M. Jevtić, and N. Arsić, "Optimal Power Flow Using a Hybrid Optimization Algorithm of Particle Swarm Optimization and Gravitational Search Algorithm", Electric Power Components and Systems, Vol. 43, No. 17, pp. 1958-1970, 2015.

[39] W. Warid, H. Hizam, N. Mariun, and N. I. Abdul-Wahab, "Optimal power flow using the Jaya algorithm", Energies, Vol. 9, No. 9, p. 678, 2016.

[40] M. Kumari and S. Maheswarapu, "Enhanced genetic algorithm based computation technique for multi-objective optimal power flow solution", International Journal of Electrical Power and Energy Systems, Vol. 32, No. 6, pp. 736-742, 2010. 